\title{
Avaliação da presença de compostos organofosforados de uso industrial em áreas do Rio Piracicaba e afluentes
}

\author{
Izabela O. Santos*, Joyce Cristale, Enelton Fagnani.
}

\section{Resumo}

Os retardantes de chama e plastificantes organofosforados (OPFRs) são aditivos encontrados em todas as matrizes ambientais. Os tratamentos de esgoto convencionais não os removem efetivamente, e consequentemente os OPFRs atingem as águas superficiais, podendo trazer riscos para os ecossistemas aquáticos uma vez que são alteradores endócrinos e neurotoxicantes. Os compostos tris (2-cloroisopropil) fosfato (TCIPP) e tris (2-butoxietil) fosfato (TBOEP) foram determinados em águas superficiais. Estabeleceu-se um plano de amostragem com um total de 12 pontos na Bacia do Rio Piracicaba, e foram realizadas três campanhas de amostragem. A avaliação dos resultados revelou maiores concentrações nos rios Quilombo e Ribeirão Tatu, refletindo o impacto antropogênico nestas áreas.

\section{Palavras-chave:}

Retardantes de chama; GC-MS; águas superficiais.

\section{Introdução}

Os retardantes de chama e plastificantes organofosforados (OPFRs) proporcionam o retardamento da combustão e/ou características mais flexíveis aos materiais. Como os OPFRs não são quimicamente ligados aos materiais, acabam sendo liberados para o meio ambiente. Estudos apontam que estas substâncias são capazes de afetar os sistemas endócrino e reprodutivo, além de algumas serem carcinogênicas (VAN DER VEEN; DE BOER, 2012, LIU et al., 2012), e também a impossibilidade da total remoção por tratamentos de esgoto convencionais (MEYER; BESTER, 2004). Assim, o objetivo deste trabalho foi o estabelecimento de um plano de amostragem representativo e análise de dois OPFRs para monitoramento da presença destes compostos em águas superficiais no Brasil. Os métodos utilizados foram a extração em fase sólida e cromatografia, realizada em um cromatógrafo de gases acoplado a um espectrômetro de massas (GC-MS).

\section{Resultados e Discussão}

Após avaliação das possíveis fontes de OPFRs na região, 12 pontos de amostragem foram estabelecidos na Bacia do Rio Piracicaba, incluindo os rios Piracicaba (PIRA 1, PIRA 2 e PIRA 3), Ribeirão Tatu (TATU 1, TATU 2, TATU 3, TATU 4 e TATU 5), Atibaia (ATI 1), Jaguari (JAG 1), Ribeirão Pinhal (PIN 1) e Quilombo (QUI 1). Os compostos tris (2-cloroisopropil) fosfato (TCIPP) e tris (2-butoxietil) fosfato (TBOEP) foram determinados nas amostras coletadas nos meses de dezembro/2018, janeiro/2019 e março/2019. A Figura 1 e 2 apresentam as concentrações de TCIPP e TBOEP determinadas em água de rio.

\section{Concentrações TCIPP}

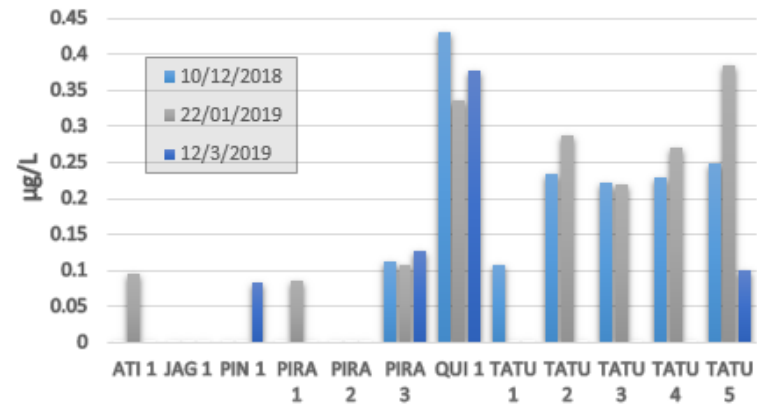

Figura 1: Concentrações de TCIPP em água de rio.

\section{Concentrações TBOEP}

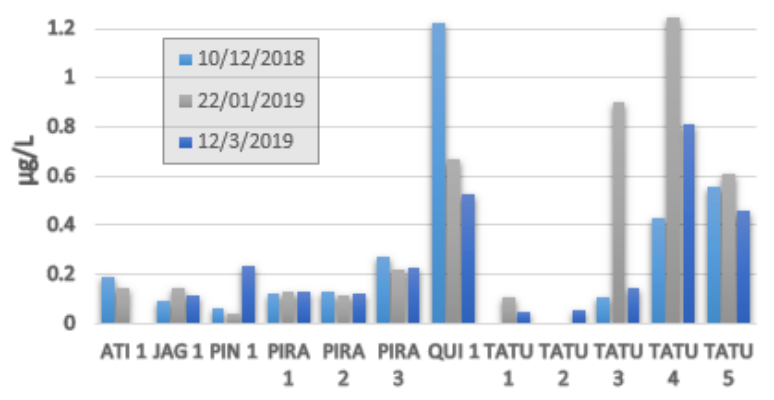

Figura 2: Concentrações do TBOEP em água de rio.

As maiores concentrações foram observadas nos pontos QUI 1 e TATU 4. Isto deve-se ao despejo de efluentes têxteis no rio Quilombo, gerado pela grande quantidade de indústrias têxteis na área, e pela maior parte da extensão do rio Ribeirão Tatu ser em zona urbana, recebendo efluentes de ETEs e escoamento superficial. As menores concentrações foram encontradas no rio Ribeirão Pinhal, provavelmente devido à sua localização afastada de centros urbanos.

\section{Conclusões}

Pelo menos um dos compostos foi encontrado em todas as amostras e em todas as épocas coletadas, provando a presença de OPFRs nas águas superficiais da região. Os pontos em que foram encontradas as maiores concentrações foram os afetados por descarga de efluentes domésticos e industriais. Este estudo demonstrou, pela primeira vez, a presença de OPFRs em águas superficiais no Brasil.

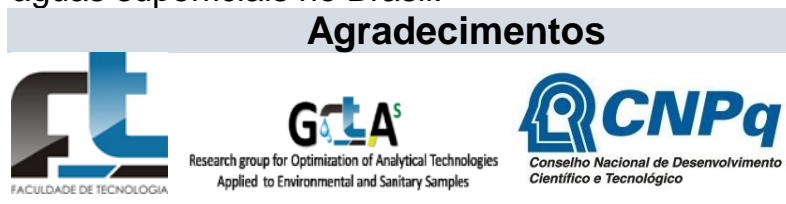

LIU, X. et al. AquaticToxicology, 2012, v. 114-115, p.173-181.

MEYER, J.; BESTER, K. Journal of Environmental Monitoring, 2004, v. 6 , n. 7, p. 599-605.

VAN DER VEEN, I.; DE BOER, J. Chemosphere, 2012, v. 88, n. 10, p. 1119-1153. 